\title{
Ivan P. Kapitalchuk
}

Head of the Chair of Physical Geography and Nature Management, Taras

Shevchenko Transdniestrian State University; Str. 25 October, 128, Tiraspol 3300,

Moldova; tel/fax: +373552 59366; e-mail: imkapital@mail.ru

\section{SUB-REGIONAL GEO-ECOLOGICAL MODEL OF A NATURAL COMPLEX}

\begin{abstract}
The paper presented herein describes a conceptual geo-ecological model of a natural complex that may be used to study polystructural landscape organization of a geographical area at the sub-regional level. The significance of the zonal component in the differentiation of natural environmental properties of Moldova's territory has been assessed.
\end{abstract}

KEY WORDS: model, landscape, geo-system, structure.

\section{INTRODUCTION}

Nearly thirty years ago, V.N. Solntsev [1981] has analyzed the progress of physical geography and established four main paradigms in the contemporary geography: geo-component, geo-complex, ecological, and geo-structural (geo-systemic). According to Solntsev [1981], the essence of the geostructural paradigm is the attempt to overcome shortcomings of other paradigms that insufficiently reflect actual complexity of landscape organization. This goal defines the core theme of the geo-systemic physical-geographical paradigm, specifically, polystructuralism of landscape organization.

The idea of spatial polystructuralism that had emerged within the concept of geo-complex paradigm [Glazovskaia, 1964; Isachenko, 1965 et al.] was further developed by K.G. Raman [1976], V.B. Sochava [1978], G. Haaze [1980], V.N. Solntsev [1981], Yu.G. Puzachenko [1985], V.S. Preobrajensky [1986], and other authors. The development of this theory can be formulated as "the development of phenomenological views on multilayered integration of the same geo-components in various natural complexes as well as on the hierarchical structure of the geographical layer as a necessary condition for its stability" [Kolomyts, 1998, p. 9]. Geosystems may be also characterized by an important temporal polystructuralism. The temporal component is expressed in aggregated control processes of different duration [Solntsev, 1981]. Both spatial and temporal structures of natural geo-systems are different from those of socio-economic systems, although they are formed of the same components [Solnysev, 1981]. This is why the geostructural approach seems to be efficient in the analysis of the interactions between landscape and socio-economic systems.

A real breakthrough that have turned the idea of the landscape polystructuralism into a well- grounded concept is the work of E.G. Kolomyts [1998] where forms of the manifestation of landscape polystructuralism in real conditions have been empirically established at the regional scale. The underlying methodology of this work is the conceptual empirical model of a natural complex implemented at the regional scale [Kolomyts, 1998].

The research effort described in this paper represents an attempt to apply the E.G. Kolomyts conceptual empirical model of a natural complex to the area at the sub-regional scale using natural-spatial organization of Moldova as a case study.

\section{CONCEPT, STRUCTURE AND PARAMETERS OF THE MODEL}

Our model is based on the conceptual landscape model developed by E.G. Kolomyts [1998] for the Russian Plain. 
The crucial elements of this model are a background and spatial geo-components that are differentiated depending upon a hierarchical level of a given geo-ecosystem or a corresponding regional mechanism of manifestation of a specific component. The background characterizes a general material-energy level of a natural-spatial system reflecting a continuous distribution of a specific feature without any sudden change. The second component of the system of structural levels of the geoecosystem organization of a territory, i.e., the frame, manifests itself when the critical "mass" of geo-component properties is reached and its background value is spatially differentiated. The frame defines a relatively closed geo-ecosystem scale-based matter and energy transfer network together with key points of break-lines for geo-streams. A system of geo-fields and streams that work at the interface of the background and a specific frame represents a processor, i.e., a part of the system responsible for exchange and transit. Geo-streams form a pattern, that is, a materialized representation of both past and current processes that define a certain state of a given geo-ecosystem within a given frame [Kolomyts, 1998].

During regional polystructural studies of the boreal ecotone -"ECOFORM" in the basin of the river Volga, the spatial differentiation of geo-systems has been conducted at a landscape level where landscapes were grouped into categories based on their types [Kolomyts, 1998]. The classification used to compile a landscape map of the former Moldavian SSR (which territory is the object of the present study) at a scale 1: 750000, has been done at a level of morphologic landscape components, i.e., districts and natural boundaries [Atlas, 1978]. That is why these morphological landscape components may be specifically viewed as elementary geo-systems at the sub-regional and local scales of the natural-spatial systems.

A transition from the regional to the sub-regional and local levels in the analysis of the landscape composition determines which parameters that characterize territory at a given scale are used. Parameters of the frame and a landscape pattern at the sub-regional geo-spatial level can be more detailed than their regional analogues. Some background parameters may be disregarded due to a decrease in the zonal component of the natural-spatial differentiation of the sub-regional geo-space.

Taking into account the discussion presented above, the initial parameters of the model for a sub-regional natural complex may be as follows:

1 - Types of geo-ecosystems.

2 - Groups of types of geo-ecosystems.

3 - Native plant associations.

4 - Ratio of areas of different parent-rock material.

5 - Ratio of areas of different soil types (sub-types).

6 - Cumulative annual radiation $(F)$.

7 - Annual radiation balance.

8 - Average annual temperature.

9 - Average January temperature.

10 - Average July temperature.

11 - Sum of temperatures above $10^{\circ} \mathrm{C}$ $\left(\Sigma t \geq 10^{\circ}\right)$.

12 - Duration of the period at $t \geq 10^{\circ}$.

13 - Average annual precipitations.

14 -Cumulative precipitation in the cold season.

15 - Cumulative precipitation during the period at $t \geq 10^{\circ}$.

16 - The Vysotsky-Ivanov humidification coefficient. 
17 - Average annual runoff.

18 - Spring runoff.

19 - Storm runoff.

20 - Maximum absolute elevation of the territory.

21 - Minimum absolute elevation of the territory.

22 - Average elevation of the territory.

23 - Average slope length.

24 - Ratio of areas with different slope steepness.

25 - Density of relief differentiation.

26 - Depth of relief differentiation.

27 - Areas affected by ravines.

28 - Depth of the carbonate deposition in soil.

29 - Chemical composition of groundwater.

30 - Soil-geochemical complexes.

31 - Soil Bonitet: properties and crop yield capacity.
32 - Parameters of anthropogenic load.

This list of the model parameters can be considered as the initial. The number and types of the model parameters can vary depending upon a specific task and scale of geo-ecosystems under investigation.

Following the E.G. Kolomyts concept [1998], parameters that describe the state of the sub-regional geo-territory under investigation have been grouped into the following blocks: hydro-climatic, geological-geomorphologic, biotic, and geo-ecosystem. These blocks, in turn, are constituent elements of the structural levels system "background - frame-pattern", which corresponds to the functional blocks of the empirical_model "condition - process structure".

The grouping of the parameters into blocks for the background, frame, and processor in some cases is rather relative. First, ascription of a parameter to one or another block of the model depends on the interpretation by a modeler of the role and place of that parameter in the process of pattern formation. Next, including the parameters into specific blocks of the model will often depend upon a geoecosystem scale. Therefore, it was crucial to adjust the model parameters to a geoecosystem scale.

Table 1. Parameters of the territory at a sub-regional scale grouped into blocks of the geo-ecological model

\begin{tabular}{|c|c|c|c|}
\hline \multirow{2}{*}{$\begin{array}{l}\text { Geo-component } \\
\text { blocks }\end{array}$} & \multicolumn{3}{|c|}{ Blocks of empirical model of a natural complex } \\
\hline & $\begin{array}{l}\text { Background and } \\
\text { Frame ("entrance") }\end{array}$ & $\begin{array}{c}\text { Processor } \\
\text { (interior geo-streams) }\end{array}$ & $\begin{array}{l}\text { Geo-ecosystem } \\
\text { pattern ("exit") }\end{array}$ \\
\hline $\begin{array}{l}\text { Exchange-transit } \\
\text { (hydro-climatic) }\end{array}$ & $\begin{array}{l}\text { Cumulative annual } \\
\text { radiation (6) }\end{array}$ & \multirow{2}{*}{$\begin{array}{l}\text { Annual radiation balance }(7) ; \\
\text { Average temperature: January (8), } \\
\text { July }(9) ; \\
\text { Total of active temperatures }(10) ; \\
\text { Duration of active temperatures }(11) ; \\
\text { Cumulative precipitations }(12-14) ; \\
\text { Humidification coefficient }(15) ; \\
\text { Drainage parameters }(16-18) \text {. }\end{array}$} & \multirow{2}{*}{$\begin{array}{l}\text { Areas affected by ravines (26), } \\
\text { Depth of carbonate } \\
\text { deposition in soil (27); } \\
\text { Chemical composition of } \\
\text { underground waters(28); } \\
\text { Soil-geochemical complexes } \\
\text { (29) }\end{array}$} \\
\hline $\begin{array}{l}\text { Conservation } \\
\text { (geological- } \\
\text { geomorphologic) }\end{array}$ & $\begin{array}{l}\text { Parent soil material } \\
\text { horizons (4); } \\
\text { Relief parameters } \\
(19-25)\end{array}$ & & \\
\hline Biotic & & Geo-ecosystem productivity (30) & $\begin{array}{l}\text { Vegetation (3); } \\
\text { Types (subtypes) of soil (5). }\end{array}$ \\
\hline $\begin{array}{l}\text { Comprehensive } \\
\text { (geo-ecosystem) }\end{array}$ & & & $\begin{array}{l}\text { Types and groups of geo- } \\
\text { ecosystems (1,2); Parameters } \\
\text { of anthropogenic load (31) }\end{array}$ \\
\hline
\end{tabular}


FITTING THE MODEL TO THE TERRITORY OF MOLDOVA AT A SUB-REGIONAL SCALE

Due to the intensive development of agriculture in the former Moldavian SSR, topsoil was the best studied natural component in the republic. As a result, the soil-ecological regionalization has been done at a microregional level. The descriptions of the microregions contain detailed descriptions not only of a top-soil structure, but also the quantitative characteristics of the relief, climate, ratio of areas of different parent-rock material, and the main types of agricultural lands. These data are best systematized by A.F. Ursu $[1980,2006]$ and used as the initial data in this research effort. Other sources were also used to fill the gaps: [Atlas, 1978; Atlas, 1988; Rymbu, 1985 etc.]

After determining the qualitative characteristics of the geo-space considered in this work, the initial parameters were classified into the blocks of the geoecological model (Table 1). The first step was the identification of the parameters of the background that reflect a continuous distribution of components without sudden change. Analysis of thematic maps [Atlas, 1978] on spatial distribution of hydroclimatic factors showed that for the territory of Moldova (that stretches for $350 \mathrm{~km}$ from north to south), these factors should be considered as spatially differentiated. It appeared that only one parameter, namely,

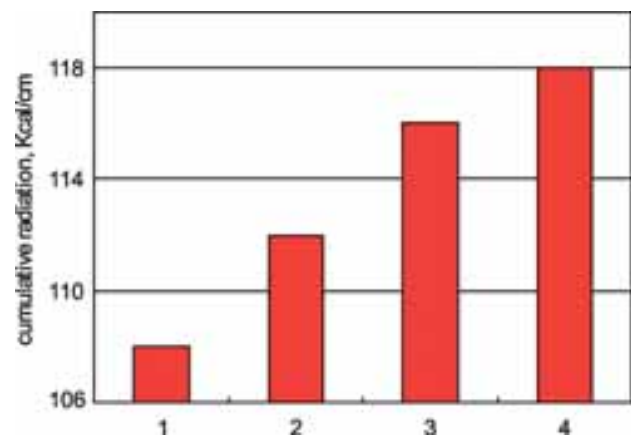

Average values of the cumulative annual radiation for the flat areas of Moldova:

1 - North-Moldavian Plateau, 2 - Balti Plain,

3 - South-Moldavian Plain, 3 - South-Bessarabian Plain the cumulative annual radiation, can be used as the background parameter for the geo-territory in this study. First, this parameter is distributed evenly, i.e., without sudden changes, within the territory in this study, with the exception of the Codry area [Atlas, 1978, p.38]. Second, the cumulative annual radiation together with the frame of the territory is a primary factor that determines both spatially differentiated temperature factors and moisture availability. As it is shown in Figure, the cumulative annual radiation increases from north to south within flat regions of Moldova, which if followed by a transition from forest-steppe to steppe and, within steppe landscapes, from rich to poor motley grass associations.

At the same time, absolute elevations generally decrease from north to south [Ursu, 1980; Ursu, 2006]. Hence, a question arises of the importance of a continuity of the zonal component for the naturalspatial organization of the geo-space in this study. In order to exclude the influence of the geological-geomorphologic frame on the assessment, it has been decided to carry out the analysis of the importance of hydro-climatic factors for the micro-regions with different background conditions and average elevations in the narrow range of $100 \mathrm{~m}$ to $150 \mathrm{~m}$. Among such parameters, we considered the average annual temperature ( $T$, in $C)$, average annual precipitation ( $Q g$, $\mathrm{mm})$, precipitation during the period with the temperatures over $10^{\circ} \mathrm{C}(\mathrm{Qt}, \mathrm{mm})$, sum of temperatures of $10^{\circ} \mathrm{C}$ and higher $\left(\Sigma t \geq 10^{\circ}\right.$, degrees), duration of the period with the temperature of $10^{\circ} \mathrm{C}$ and higher (Pt, days), and the Vysotsky-Ivanov humidification coefficient $(\mathrm{Kw})$. The results are presented in Table 2.

As shown in Table 2, mean values of hydroclimatic parameters in different background conditions of solar radiation do not very significantly. Variation coefficients for the general sampling do not exceed 3\% of the mean value. The statistical calculations have also confirmed the random nature (i.e., statistically insignificant) of deviations between mean values of hydro-climatic parameters (significance value $p=0.01$ ). 
Table 2. Statistic characteristics of hydro-climatic factors of the territories with the average elevation of $100 \mathrm{~m}$ to $150 \mathrm{~m}$ for different background values of the cumulative annual radiation $\left(F, \mathrm{Kcal} / \mathrm{sm}^{2}\right)$

\begin{tabular}{|c|c|c|c|c|c|c|}
\hline \multirow{2}{*}{$\begin{array}{c}\text { Statistical } \\
\text { characteristics }\end{array}$} & \multicolumn{6}{|c|}{ Hydro-climatic factors } \\
\hline & $T$, degree & $Q g, \mathrm{~mm}$ & $Q t, \mathrm{~mm}$ & $\begin{array}{l}\Sigma t \geq 10^{\circ}, \\
\text { degrees }\end{array}$ & Pi, days & $K w$ \\
\hline \multicolumn{7}{|c|}{$F \leq 112$} \\
\hline Sampling & 6 & 6 & 6 & 6 & 6 & 6 \\
\hline Mean value & 8.92 & 466.0 & 357.5 & 3072.5 & 177.0 & 0.580 \\
\hline Standard deviation & 0.13 & 7.4 & 6.6 & 30.3 & 1.1 & 0.023 \\
\hline \multicolumn{7}{|c|}{$112<F \leq 114$} \\
\hline Sampling & 11 & 11 & 11 & 11 & 11 & 11 \\
\hline Mean value & 8.78 & 474.8 & 365.1 & 3036.8 & 175.7 & 0.589 \\
\hline Standard deviation & 0.09 & 5.5 & 5.0 & 23.9 & 0.8 & 0.011 \\
\hline \multicolumn{7}{|c|}{$114<F \leq 116$} \\
\hline Sampling & 5 & 5 & 5 & 5 & 5 & 5 \\
\hline Mean value & 8.88 & 468.6 & 359.6 & 3064.0 & 176.4 & 0.578 \\
\hline Standard deviation & 0.13 & 6.5 & 5.5 & 24.1 & 0.9 & 0.015 \\
\hline \multicolumn{7}{|c|}{$F>116$} \\
\hline Sampling & 10 & 10 & 10 & 10 & 10 & 10 \\
\hline Mean value & 8.86 & 469.9 & 369.7 & 3057.5 & 176.3 & 0.580 \\
\hline Standard deviation & 0.17 & 9.7 & 8.6 & 40.3 & 1.3 & 0.019 \\
\hline \multicolumn{7}{|c|}{ Total sampling } \\
\hline Sampling & 32 & 32 & 32 & 32 & 32 & 32 \\
\hline Mean value & 8.84 & 470.9 & 361.7 & 3053.2 & 176.2 & 0.583 \\
\hline \multirow{2}{*}{ Standard deviation } & 0.14 & 8.1 & 7.2 & 33.5 & 1.1 & 0.017 \\
\hline & 1.6 & 1.7 & 2.0 & 1.1 & 0.6 & 2.9 \\
\hline
\end{tabular}

Therefore, the background values of the cumulative annual solar radiation on the territory of Moldova are not statistically important for the differentiation of natural conditions and, as a result, for its spatial geo-ecosystem structure. The geologicalgeomorphologic frame is the main factor in the landscape organization of the subregional geo-space of Moldova.

\section{CONCLUSION}

Geo-ecological models of geo-ecosystems of the territory of Moldova at a local level (i.e., micro-regions and physical-geographical areas) were created using the concept presented above. However, the creation of these models alone was not a goal in itself. These models serve as the basis for qualitative assessments of mono- and polysystem studies of the landscape organization of the territory.

\section{ACKNOWLEDGMENT}

The author is grateful to B.I. Kochurov who performed some of the analyses and helpful discussion. The able technical assistance provided by O.K. Iliasenco is gratefully acknowledged. 


\section{REFERENCES}

1. Atlas of Moldavskaya SSR. (1978) M.: GUGiK (the Head Office of Geodesy and Cartography of USSR), $131 \mathrm{p}$.

2. Atlas of Soils of Moldaviya. (1988) I.A.Krupenikov (Ed.) Kishinev: Shtiintsa, 176 p.

3. Glazovskaia, M.A. (1964) Geoclimatic Fundamentals of Typology and Research Methods of Natural Landscapes. M.: Moscow State University, 231 p.

4. Haaze, G. (1980) Study of topographic and choric structures, of their dynamics, and of development of landscape systems. In: Structure, dynamics, and development of landscapes. M.: Institute of Geography of the AN SSSR, pp. 57-81.

5. Isachenko, A.G. (1965) Fundamentals of Landscape Science And Physicogeographical Zonation. M.: Vysshaia skola, $327 \mathrm{p}$.

6. Kolomyts, E.G. (1998) Polymorphism of landscape-zonal systems. Puschino. ONTI PNTS RAN, $311 \mathrm{p}$.

7. Preobrajensky, V.S. (1986) Structure and organization of landscapes (preprint). M.: Institute of Geography of the AN SSSR, 20 p.

8. Puzachenko, Yu.G. (1985) Spatial-temporal hierarchy of geosystems from the standpoint of the theory of oscillations. Voprosy Geografii. № 127. Geosystem Modeling. - M.: Mysl, pp. 96-111.

9. Raman, K. (1976) Background of understanding of a geo-complex as a spatial-polystructural unity. International Geography-76. General Physical Geography. M.: International Geographical Congress, pp. 18-22.

10. Rymbu, N.L. (1985) Natural conditions and resources of Moldavskaya SSR. Kishinev: Shtiintsa, $192 \mathrm{p}$.

11. Sochava, V.B. (1978) Introduction to Geosystem Science. Novosibirsk: Nauka, 319 p.

12. Solntsev, V.N. (1981) Systemic Organization of Landscapes (Problems of Methodology and Theory) - M.: Mysl, 239 p.

13. Ursu, A.F. (1980) Soil-Ecological Microzonation of Moldavia. I.A.Krupenikov (Ed.). Kishinev: Shtiintsa, $208 \mathrm{p}$.

14. Ursu A. (2006) Raionele pedogeografice şi particularităţile regionale de utilizare şi protejare a solurilor. - Ch.: Tipogr. Acad. De Şt., 232 p.

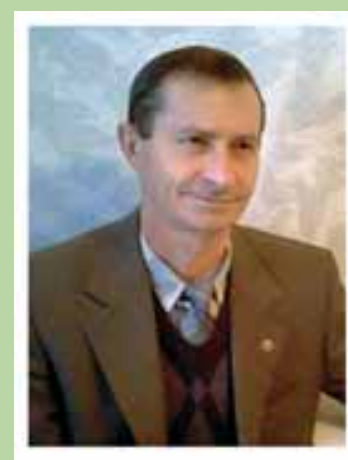

Ivan P. KAPITALCHUK was born in 1954. He is Director of the Institute of Ecology and Natural Resources and Head of the Chair of Physical Geography and Nature Management of the Transdniestrian State University (Tiraspol, Moldova). Dr. Kapitalchuk graduated from Odessa Hydrometeorological Institute in 1981where he defended his Ph.D. dissertation (in geography) "Study of Structure and Evolution of Heavy Convective Clouds during their Natural Development and Weather Modification by Dual Polarization Radar" (the research work was performed at Central Aerological Observatory (Dolgoprudnyi - Moscow region). Dr. Kapitalchuk has published 100 scientific works in the fields of ecology and landscape organization of territories. 